\title{
In vitro release
}

In vitro release study of Taxotere, DPL and YDPL was carried out using a dialysis bag method using phosphate buffer $\mathrm{pH} 7.4$ with $0.2 \% \mathrm{w} / \mathrm{v}$ tween 80 as release medium. The dialysis bag (MWCO $50 \mathrm{kD}$, Spectrum lab, USA) filled with $1 \mathrm{ml}$ of DTX formulation was tied to the paddle of USP dissolution apparatus II $\left(50 \mathrm{rpm}, 37^{\circ} \mathrm{C}\right)$. Samples were withdrawn at $0.5,1,2,4,8,12$ and $24 \mathrm{~h}$ and DTX content was analyzed by HPLC. As shown in Fig. S1, both DPL and YDPL showed nearly similar release of DTX over the period of $48 \mathrm{~h}$. Taxotere solution showed complete release of DTX within first $2 \mathrm{~h}$ while liposomal formulation showed sustained release with $<50 \%$ DTX release in $48 \mathrm{~h}$. However, complete release is expected in vivo due to degradation of liposomes. YSA coating has no significant impact on DTX release.

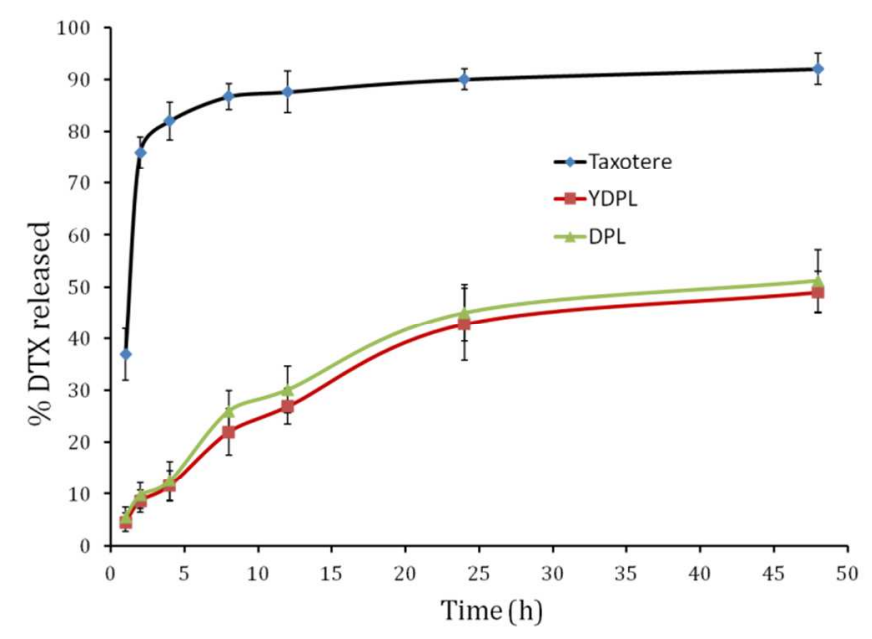

Fig. S1: In vitro release of Taxotere, DPL and YDPL in USP apparatus II using dialysis bag (MWCO $50 \mathrm{kD}$ ) in phosphate buffer $\mathrm{pH} 7.4$ with $0.2 \% \mathrm{w} / \mathrm{v}$ tween 80 at $37^{\circ} \mathrm{C}(\mathrm{n}=3)$. 